\title{
Participatory Action Research with Self-Help Groups: An Alternative Paradigm for Inquiry and Action ${ }^{1}$
}

\author{
Mark A. Chesler ${ }^{2}$ \\ University of Michigan
}

\begin{abstract}
Presents participatory action research $(P A R)$ as a scientific paradigm most relevant for inquiry and action with self-help groups. "Subjects" individual and collective involvement in the design, conduct, and utilization of research, and scientists' involvement in action to improve group functioning, are among the hallmarks of PAR. Such an approach is most consistent with self-help characteristics and ideology: highly participative membership, aprofessional leadership, localist and grass-roots orientation, and respect for experience-based knowledge. Conducting research and action for change that simultaneously generates useful knowledge and advances group goals requires new scientific roles and techniques. The orthodoxy of the conventional scientific paradigm is problematic for productive inquiry about self-help and for aiding self-help groups.
\end{abstract}

My associates in the Candlelighters Childhood Cancer Foundation say that much of the research on self-help is like popcorn. That is, it looks good, it tastes good, it goes down easy, it takes up space, but it is not very nutritious. In their view, and mine, much of this research neither

${ }^{1}$ In preparing this paper I benefited enormously from the suggestions of David Bargal, Thomasina Borkman, Barry Checkoway, Thomas Powell, and Margaret Weigers. An informal version of this paper was presented at the Planning Session on Collaboration with Parent Groups, sponsored by the National Project on Self-Help Groups, funded by a grant from Maternal and Child Health (MCJ-009127).

${ }^{2}$ All correspondence should be sent to Mark A. Chesler, Program on Conflict Management Alternatives, Center for Research on Social Organization, The University of Michigan, 4016 LSA Building, Ann Arbor, Michigan 48109-1382. 
addresses nor answers the questions of greatest concern to self-helpers. Although social scientists have made many contributions to the literature on self-help, these contributions often have failed to be very helpful. Since many of the social scientists conducting this research are committed to the self-help movement, concerned about the future of these groups and organizations, and desirous of producing valid academic knowledge, this is a serious problem.

Why is so much of the research produced by a friendly scientific community marginal or not useful to people active in self-help processes and groups? No doubt there are many answers to this question, but one is that the conventional research paradigm and its favored methods often do not fit the nature of self-help groups and their goals for information or action. The alternative approach of participatory action research (PAR) is quite congenial with the highly participatory and experiential culture and goals of self-help. Moreover, it employs technologies of data collection and analysis that are congruent with the reliance on local wisdom and lay leadership that runs through the self-help movement. Finally, the ways in which participatory action research generally utilizes research findings is more consistent with the organizational structures and action needs, as well as empowerment potentialities, of self-help groups.

\section{THE CONVENTIONAL SOCIAL SCIENTIFIC MODEL}

There are many versions of the scientific method, and different versions are more or less applicable for different researchers, in different situations, studying different phenomena. But the choice of Method, or methods, is not trivial; epistemologies of science and techniques of data collection and analysis have profound impact on what we study, how we study it, how we relate to people or "subjects," and what actions may be taken on the basis of findings. The social scientific academy, however, is dominated by one version of the scientific method. Drawing heavily on the physical sciences' positivist and deductive approach, as championed by early social scientists Comte and Durkheim, it stresses the search for general laws, formal and a priori hypotheses, neutrality with regard to moral issues, standardized assessment devices, the reduction of observed reality into constituent parts, and the establishment of "distance" and nonintervention between the investigator and the field of study (Lincoln \& Guba, 1985). As Cancian and Armistead indicated (1990): "Knowledge is obtained by using the methods of the physical sciences, and attempting to form general laws of society based on rigorous reasoning and systematic, reproducible observations ... [it] requires experts who are trained 
to be detached, unemotional and apolitical" (p. 11). Whyte (1986) summarized the conventional method's lack of involvement in action for change: "In general, social scientists have refrained from linking research directly with action. We have been afraid that our involvement in action will contaminate the scientific basis of our research" (p. 556). Various advocates and critics of the positivist and deductive approach that is at the heart of this "conventional method" differ in particulars, but almost all would agree to these central canons (Lincoln \& Guba, 1985; Rowan, 1981).

Few researchers are "ideal types" - positivists or an alternative and abstract debates about positivism's advantages and disadvantages often establish (and disparage) straw models (Meehl, 1986). But a general set of assumptions rooted in positivism does guide most academic social science, and the result has been a "methodological prejudice [for] quantitative measurement, experimental design and parametric statistical analysis" (Patton, 1978, p. 203). As useful as these techniques may be, and as dominant as they are in social scientific training programs and journals, they are not the only valid methods of scientific inquiry.

One alternative to this conventional model of academic research is "applied research." In this tradition the (positivist) epistemological assumptions and methods of inquiry remain much the same, but the intended audience and use of findings differ. The goal of much applied research is to generate scholarly findings that can be used by others to help improve personal or organizational functioning, to evaluate service delivery programs, or otherwise to alter the social system (Bickman, 1982; Freeman, Dynes, Rossi, \& Whyte, 1983). As Rossi, Wright, and Wright (1978) make the case: "Applied research is directed to the solution of some real world problem ... [with] variables amenable to manipulation by policy makers" (pp. 173-174). They and other applied researchers, however, are still greatly concerned with "meeting current methodological standards," those promulgated and legitimized by conventional criteria. Thus, distance and noninvolvement from the field may be eschewed in favor of having an impact on policy or practice, but deductive and quantitative methods, predictive control and theory testing, and objectivity and neutrality, generally still are priorities.

Other, more inductive or phenomenological and qualitative approaches, as well as a variety of activist or advocate approaches, may offer equally valid insights and systematic understanding, as well as guides for action. In fact, some of these latter approaches utilize methods that are more appropriate for generating both academic and practically useful knowledge for researchers and for self-helpers. 


\section{AN ALTERNATIVE PARADIGM}

In "action research" a commitment by the researcher to personal action-taking, and to improving the human social condition directly, is an integral and necessary component of the knowledge generation process. The central features of action research involve a repetitive and cyclical process of diagnosis, analysis, action, and evaluation; a high degree of cooperation and involvement between researcher and practitioner, with constant feedback loops; and a commitment to use findings to solve social problems (Chein, Cook, \& Harding, 1948; Elden, 1981; Lewin, 1946; Sanford, 1970; Tichy \& Friedman, 1983). This style of work may begin with action that is then systematically documented, analyzed, and evaluated, or with research that is subsequently translated into efforts for change. The cyclical flow of action research, and scientists' commitment to some form of personal involvement in creating change, distinguish it from applied research.

Within the tradition of action research there also are major differences in the ways scholar-activists attempt to serve both the academic and practice communities (Brown \& Tandon, 1983). Participatory action researchers emphasize conducting action research on a fully participatory basis with subjects - called coresearchers (Carr \& Kemmis, 1983; FalsBorda, 1984; Gaventa, 1988). As Gaventa (1988) suggested: "Research is seen not only as a process of creating knowledge, but simultaneously as education and development of consciousness and of mobilization" (p. 19). Such action objectives are built into the research design from the beginning, with the initiative and participation of the coresearchers. This work stresses respect for and reliance upon the needs and expertise of practitioners and citizens involved in the issues, sites, or problems under study, and involves them in the direction of the entire endeavor from start to finish. Only if people who are the direct beneficiaries of relevant research are so involved can they help inform and direct the work, monitor it, and make the best use of it in social change endeavors. Through participation, local informants, citizens, and activists can increase the researcher's knowledge base directly and consciously. They also can learn new skills in gathering and analyzing information, thus laying bare the workings of the social systems of which they are a part and improving their strategic decision-making (Brown \& Kaplan, 1981; Susman \& Evered, 1978). Such participation in knowledge creation often is consciousness raising and empowering (Freire, 1973; Israel, Schurman, \& House, 1989). According to Brown and Tandon (1983), the focus on participation and empowerment, on changing the social structure, and on dealing with issues of institutional control and conflict 
are major characteristics distinguishing PAR from other forms of action research.

Participatory action research also self-consciously attempts to counter researchers' monopoly over the knowledge generation process, and thus the cultural forms, language, and policies that are derived from research. Cancian and Armistead (1990), Gaventa (1988), and Hall, Gillette, and Tandon (1982) discuss the many ways in which scientists' and elites' control of the means of knowledge production may help disempower poor people, women, and people of color.

\section{COMPARING THE PARADIGMS}

I illustrate some of the differences between participatory action research (PAR) and the most conventional academic research process in Table I. Although I have created a dichotomous table (for reasons of space rather than clarity), a continuum of options (e.g., nonpositivist academic research, phenomenological research, evaluation research, applied research, action research, etc.) exists between these poles (Rowan, 1981).

As Table I suggests, the participatory character of PAR involves subjects in becoming coresearchers; it also requires researchers to enter the world of the people being studied. As Whyte, Greenwood, and Lazes (1989) argued, "Science is not achieved by distancing oneself from the world ... the greatest conceptual and methodological challenges come from engagement with the world" (p. 515). The defense against being swallowed up by this engagement is a form of "dynamic objectivity" (Keller, 1985), one in which the researcher reflexively encounters both herself and the field of inquiry. In contrast, the conventional researcher is most likely to exclude subjects from significant knowledge of or participation in the research project (except as required for human subject consent processes) and to exclude himself from direct efforts to alter the field of inquiry, in order to maintain "objectivism" (Keller, 1985) through detachment and control.

The conventional research paradigm usually poses a specific and detailed inquiry agenda prior to entering the field, one typically based on theories of personal and group processes. Social service agencies and governmental funders, and social scientists funded by them, primarily want to know whether self-help groups work - whether members have better mental or physical outcomes as a result of participation - or whether they work "better" than professional service systems (Jacobs \& Goodman, 1989). They 


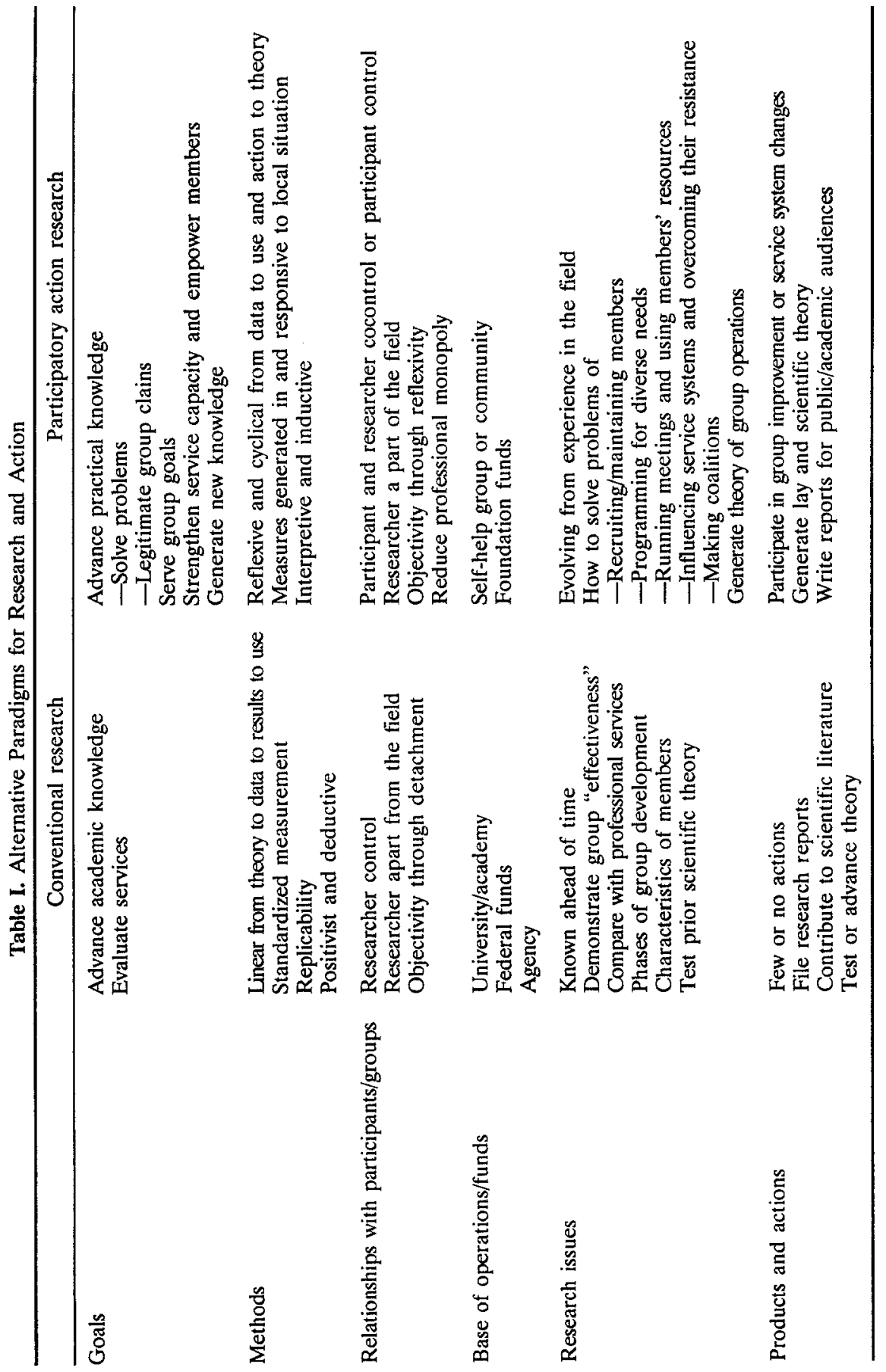


also usually are interested in theories explaining the characteristics of group participants and group operations.

The central foci of participatory action research studies are more likely to evolve from interactions with members and groups in the field. Primary concerns of group leaders seldom focus on the assessment of effectiveness - that they already "know." They are more interested in solving problems of group functioning: leadership, recruitment, maintenance, fund-raising, programming to meet members' needs, and working with (or changing) social service agencies. On this basis, conceptual principles and theory can be generated that inform and explain member choices and group dynamics as well as direct future actions.

Governmental agencies, often staffed or advised by members of the social scientific academy, are primary sources of funds for conventional research. In addition, human service agencies interested in evaluating their own or alternative service delivery systems may fund conventional academic and applied research ventures. The methodological prejudice in favor of positivist and quantitative methods often makes it difficult for researchers wishing to use qualitative or PAR methods to gain access to such funds (Lidz \& Ricci, 1990). Thus, these researchers may ally themselves with and in, or be sought out by, alternative service delivery systems and community groups themselves.

Research conducted within the conventional paradigm may or may not lead to action for change; such research often concludes with articles in appropriate scientific journals or a technical report filed with agency or governmental offices. The very concern for detachment and disengagement generally precludes action-taking, and certainly action that might challenge the power of established agencies. Participatory action researchers may have undertaken action or change efforts prior to or simultaneous with the research endeavor. Acting with or on behalf of the groups with which they are conducting research, they typically are personally engaged in helping to utilize the findings from research studies and coorganizing and coparticipating in change efforts.

\section{PARTICIPATORY ACTION RESEARCH WITH SELF-HELP GROUPS}

Why is this brief discussion of alternative paradigms for social scientific research (and public action) particularly relevant to research on/with /for self-help groups? Self-help groups are distinctive social phenomena. They are more like voluntary grass-roots organizations or nascent social movements than rationalized bureaucracies (Katz, 1981; Killilea, 1976). 
Moreover, as Borkman suggested (1984), "each self-help group constructs its own experiential paradigm - of the problem and the means to resolve it" (p. 208). The tremendous variety in organizational form and function, even in local units of a single national umbrella organization, means that preestablished and standardized research questions, measures, topics, and approaches may fail to adequately tap or be relevant to real-life heterogeneity (Levy, 1984).

The processes that occur in self-help groups are more like private interactions in a family or intimate relationship than a secondary social relationship. Thus, a researcher's access may require clear identity or identification with the condition at hand, and intimate knowledge of the language and styles that code in-group/out-group perceptions. Jacobs and Dopkeen (1990) argued that researchers may improve their access and learn more by becoming members of the groups they study, and then "studying him or herself" (p. 171). In my own work with groups formed by/for families of children with cancer, I have found it very helpful to be a parent of a child with cancer, an organizer and former leader of a local self-help group, and a board member of the Candlelighters Childhood Cancer Foundation, a national organization of self-help groups for families of children with cancer (Chesler, 1990; Yoak \& Chesler, 1985). This personal history has provided me with special knowledge of individual and group situations, and with the legitimacy and credibility to ask and to be told about intimate organizational details. My commitment to advance these groups' agendas for service and change has led to the use of research findings in training sessions for leaders, (re)education sessions for medical and health care professionals, local recruiting and organizing efforts, and protests or challenging movements (Chesler, 1991).

Since issues of personal and collective empowerment are crucial in self-help groups, inquiry methods and actions for change that explicitly seek to empower participants (see earlier comments by Cancian and Armistead, 1990; Gaventa, 1988; and Rappaport et al., 1985) become extremely relevant and important.

Both the structure and process of self-help organizations suggest that their reality cannot be known or predicted ahead of time or from "the outside." Standardized or highly controlled research designs simply may not be feasible; or, in order to be feasible, may overlook or inappropriately squeeze group realities into oversimplified models. Small grass-roots organizations responding to people in pain may create a buzzing confusion of interactions and events (late night phone calls, crying and hand-holding sessions, time spent painting houses together, etc.), events distinctively suited to people's unique needs and circumstances, 
and interactions invisible or incomprehensible to the outside observer or the short-term visitor.

Meaningful access to the private lives of people suffering from an illness, or from some socially stigmatized condition, is a matter of carefully negotiated privilege. It is not easy to get, is delicate to maintain, and generally implies some reciprocal moral or ethical exchange. The Federation for Children with Special Needs, a coalition of self-help groups of parents of children who are ill or who have disabilities, explicitly warns against participating in research under pressure, when the research purposes are unclear, or when it is not clear how the results will be used (Anderson, 1988; see also Report of Consensus Conference on Principles of Family Research, 1989).

Since many self-help groups develop explicitly to fill gaps or create change in the service delivery system, they are not likely to trust establishment-based researchers, even applied or action researchers, and especially not researchers embedded in the professional bureaucracy delivering services people feel are inadequate. This is undoubtedly one explanation for the resistance to research reported by such sensitive self-help scholars as Lieberman and Borman (1979), Powell (1987), and Rappaport et al. (1985). Groups and individuals struggling for legitimacy and influence, or simply wishing to preserve their privacy, may require some degree of control over researchers' freedom to investigate, to interpret and publish their results, and some evidence of researchers' commitment to their partisan cause.

Respect for the personal struggle, experiential wisdom, and emergent social dynamics embodied in the self-help process requires researchers to cast a skeptical eye on professional expertise and power (including their own). It emphasizes the existence of a "sharp bifurcation between expertise, based on the study of a problem, and experience, the subjective living of the problem" (Gaventa, in press, p. 139). Although Gaventa is talking here about the nature of PAR, he might as well be describing the fundamental culture and ideology of the self-help movement (Borkman, 1990).

These distinctive opportunities and constraints in research with self-help groups require the development and use of different methods of social inquiry and action. The principles underlying participatory action research fit quite well with the hoped-for goals of self-help group involvement: member/informant participation in the design and operation of activities, local and grass-roots orientation, freedom from professional control, opportunities to learn new skills, participation in new social processes, attaining outcomes of consciousness raising and empowerment. The utility of these participatory research processes have 
been borne out in the work of a small but growing group of researchers (Chesler, 1990; Lavoie, 1984; Rappaport et al., 1985; Wollert, Knight, \& Levy, 1984).

The data-gathering methods used in participatory action research with self-help groups and organizations are not limited. They can and have included questionnaires, extended interviews or conversations, participant observations, personal oral histories, retrospective histories of the group, reviews of meeting minutes and historic records, ethnographic case studies, peoples'/leaders' "stories," personal reflections on group experiences, and so forth. The key issue is not data-gathering mode per se but the collaborative conditions of goal setting, data gathering and analysis, and using research outcomes. Key principles for conducting this kind of research include development of trust, demonstrated knowledge of the personal experiences of group members and of group processes, commitment to serve the group, joint development of research and action agendas and techniques, efforts to validate findings with/by group members, and accountability to the informant group. Without collaborative and participatory procedures, not only are group members' interests easily violated but researchers increase their distance from the immediate experience of group members so substantially that they risk being out of touch with the reality of local knowledge and experience.

\section{CONCLUSION}

I have not sought here to make a case for participatory action research as the only mode for inquiry and action with self-help groups, but to raise issues that may help counter the dominance of the conventional model and encourage a more pluralistic scientific enterprise. Researchers must be competent in and free to use (or try to use) whatever paradigms and techniques best fit their own epistemological preferences, the phenomena they wish to understand, and the goals and resources they and their coparticipants have. In particular, the assumptions and operating styles associated with PAR seem especially relevant and useful for inquiry and action that can advance knowledge about, and contribute to the effectiveness of, self-help groups. Dogma about "the proper scientific method" may suit the current scientific establishment and governmental funding agencies, but it does not necessarily lead to good research, research that is valid and useful to the scholarly community and to the selfhelp movement. 


\section{REFERENCES}

Anderson, B. (1988). Considering whether to participate in research. Boston: Federation for Children with Special Needs. [mimeo]

Bickman, L. (Ed.) (1982). Applied social psychology annual (Vol. 3). Beverly Hills: Sage.

Borkman, T. (1984). Mutual self-help groups: Strengthening the selectively unsupporting personal and community networks of their members. In A. Gartner \& F. Riessman (Eds.), The self-help revolution. New York: Human Sciences.

Borkman, T. (1990). Experiential, professional and lay frames of reference. In T. Powell (Ed.), Working with self-help. Washington, DC: National Association of Social Workers.

Brown, D., \& Kaplan, R. (1981). Participative research in a factory. In P. Reason \& J. Rowan (Eds.), Human Inquiry. New York: Wiley.

Brown, D., \& Tandon, R. (1983). Ideology and political economy in inquiry: Action research and participatory research. Journal of Applied Behavioral Science. 19, 277-294.

Cancian, F., \& Armistead, C. (1990). Participatory research: An introduction. Irvine, CA: Department of Sociology, UC-Irvine. [mimeo]

Carr, W., \& Kemmis, S. (1983). Becoming critical: Knowledge through action research. Victoria, Australia: Deakin University Press.

Chein, I., Cook, S., \& Harding, J. (1948). The field of action research. American Psychologist, 3, 43-50.

Chesler, M. (1990). Action research in the voluntary sector: A case study of scholar-activist roles in self-help groups. In S.. Wheelan, E. Pepitone, \& V. Abt (Eds.), Advances in field theory. Beverly Hills: Sage.

Chesler, M. (1991). Mobilizing consumer activism in health care: The role of self-help groups. In Research in social movements, Conflict and change, 13, 275-305.

Elden, M. (1981). Sharing the research work: Participative research and its role demands. In P. Reason \& J. Rowan (Eds.), Human inquiny. New York: Wiley.

Fals-Borda, O. (1984). Participatory action research. Development: Seeds of Change, 2, 18-20.

Freeman, H., Dynes, R., Rossi, P., \& Whyte, W. (Eds.). (1983). Applied sociology. San Francisco: Jossey-Bass.

Freire, P. (1973). Education for critical consciousness. New York: Seabury.

Gaventa, J. (1988). Participatory research in North America. Convergence, 21(2/3), 41-46.

Gaventa, J. (in press). The powerful, the powerless and the experts: Knowledge struggles in an information age. In P. Park, B. Hall, \& T. Jackson (Eds.), Participatory research in America.

Hall, B., Gillette, A., \& Tandon, R. (1982). Creating knowledge: A monopoly. New Delhi and Toronto: Society for Participatory Research and International Council for Adult Education.

Israel, B., Schurman, S., \& House, J. (1989). Action research on occupational stress: involving workers as researchers. International Journal of Health Services, 19, 135-155.

Jacobs, J., \& Dopkeen, L. (1990). Risking the qualitative study of risk. Qualitative Sociology, $13(2), 169-181$.

Jacobs, M., \& Goodman, G. (1989). Psychology and self-help groups. American Psychologist, $44,536-545$.

Katz, A. (1981). Self-help and mutual aid: An emerging social movement? Annual Review of Sociology, 7, 129-155.

Keller, E. (1985). Reflections on gender and science. New Haven, CT: Yale University Press.

Killilea, M. (1976). Mutual help organizations: Interpretations in the literature. In R. Caplan \& M. Killilea (Eds.), Support systems and mutual help. New York: Grune \& Stratton.

Lavoie, F. (1984). Action research: A new model of interaction between the professional and self-help groups. In A. Gartner \& F. Riessman (Eds.), The self-help revolution. New York: Human Sciences.

Levy, L (1984). Issues in research and evaluation. In A. Gartner \& F. Riessman (Eds.), The self-help revolution. New York: Human Sciences.

Lewin, K. (1946). Action research and minority problems. Journal of Social Issues, 2(4), 34-46. 
Lidz, C., \& Ricci, F. (1990). Funding large-scale qualitative sociology. Qualitative Sociology, 13(2), 113-126.

Lieberman, M., \& Borman, L. (Eds.) (1979). Self-help groups for coping with crisis. San Francisco: Jossey-Bass.

Lincoln, Y., \& Guba, E. (1985). Naturalistic inquiry. Beverly Hills: Sage.

Meehl, P. (1986). What social scientists don't understand. In D. Fiske \& R. Schweder (Eds.), Metatheory in social science. Chicago: University of Chicago Press.

Patton, M. (1978). Utilization-focused evaluation. Beverly Hills: Sage.

Powell, T. (1987). Self-help organizations and professional practice. Silver Spring, MD: National Association of Social Workers.

Rappaport, J., Seidman, E., Toro, P., McFadden, L., Reischel, T., Roberts, L., Salem, D., \& Zimmerman, M. (1985). Collaborative research with a mutual help organization. Social Policy, 15(3), 12-24.

Report of Consensus Conference on Principles of Family Research. (1989). Lawrence, KS: National Institute on Disability and Rehabilitative Programs and the Beach Center on Families and Disability.

Rossi, P., Wright, J., \& Wright, S. (1978). The theory and practice of applied social research. Evaluation Quarterly, 2(2), 171-192.

Rowan, J. (1981). A dialectical paradigm for research. In P. Reason \& J. Rowan (Eds.), Human inquiry. New York: Wiley.

Sanford, N. (1970). Whatever happened to action research? Joumal of Social Issues, 26, 3-23.

Susman, G., \& Evered, R. (1978). An assessment of the scientific merits of action research. Administrative Science Quarterly, 23, 582-603.

Tichy, N., \& Friedman, S. (1983). Institutional dynamics of action research. In R. Kilman \& C. Thomas (Eds.), Producing useful information for organizations. New York: Praeger.

Whyte, W., Greenwood, D., \& Lazes, P. (1989). Participatory action research. American Behavioral Scientist, 32, 513-551.

Whyte, W. (1986). On the uses of social science research. American Sociological Review, 51, $551-563$.

Wollert, R., Knight, B., \& Levy, L. (1984). Make today count: A collaborative model for professionals and self-help groups. In A. Gartner \& F. Riessman (Eds.), The self-help revolution. New York: Human Sciences.

Yoak, M., \& Chesler, M. (1985). Alternative professional roles in health care delivery: Leadership patterns in self-help groups. Journal of Applied Behavioral Science, 21, 427-444. 